\title{
Value Proposition Design
}

\section{5}

Universitas Bina Nusantara

Konten : Canvas, Design, Test, \& Evolve

Referensi : Alexander Osterwalder, Yves Pigneur, Greg Bernarda \& Alan Smith (2014)

Value Proposition Design, John Wiley \& Sons, Inc.

\section{Canvas}

- Value Map

- Customer Profile

- Fit

$\bullet$
Khrisna Sentanu Al Ghoni Pramono

Dosen Pembimbing : Agung Purnomo
Design

- Starting Point

- Making Choices

- Prototyping Possibilities

- Understanding Customers

- Finding The Right Business Model
Test

- What To Test

- Testing Step By Step

- Experiment Library

- Bring It All Together
Evolve

- Create Allignment

- Measure And Monitor

- Improve Relentlessly

- Reinvent Yourself Constantly 